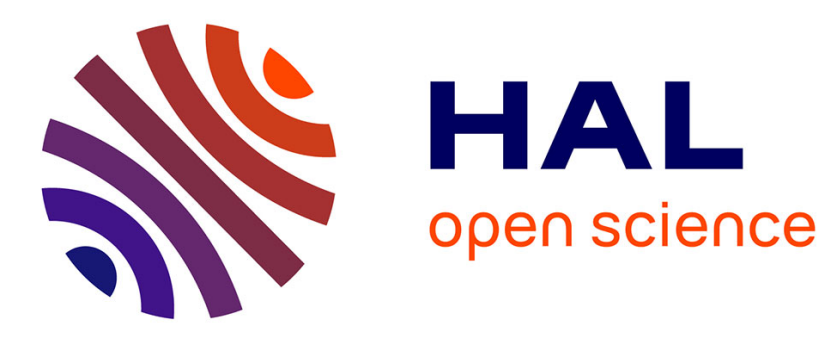

\title{
Long-term results of custom cementless-stem total hip arthroplasty performed in hip fusion
}

\author{
Xavier Flecher, Matthieu Ollivier, Pascal Maman, Sebastien Pesenti, \\ Sebastien Parratte, Jean-Noël Argenson
}

\section{- To cite this version:}

Xavier Flecher, Matthieu Ollivier, Pascal Maman, Sebastien Pesenti, Sebastien Parratte, et al.. Longterm results of custom cementless-stem total hip arthroplasty performed in hip fusion. International Orthopaedics, 2018, 42 (6), pp.1259-1264. 10.1007/s00264-018-3762-9 . hal-01960501

\section{HAL Id: hal-01960501 \\ https://hal.science/hal-01960501}

Submitted on 17 Apr 2019

HAL is a multi-disciplinary open access archive for the deposit and dissemination of scientific research documents, whether they are published or not. The documents may come from teaching and research institutions in France or abroad, or from public or private research centers.
L'archive ouverte pluridisciplinaire HAL, est destinée au dépôt et à la diffusion de documents scientifiques de niveau recherche, publiés ou non, émanant des établissements d'enseignement et de recherche français ou étrangers, des laboratoires publics ou privés. 


\title{
Long-term results of custom cementless-stem total hip arthroplasty performed in hip fusion
}

\author{
Xavier Flecher ${ }^{1,2}$ \& Matthieu Ollivier ${ }^{1,2,3}$ \& Pascal Maman ${ }^{1,2}$ \& Sébastien Pesenti ${ }^{1,2}$ \& Sébastien Parratte ${ }^{1,2}$ \& \\ Jean-Noël Argenson ${ }^{1,2}$
}

\begin{abstract}
Introduction Due to complex anatomical considerations, results of cementless-stem total hip arthroplasty (THA) in hip fusion remain controversial compared with conventional THA. We therefore aimed to analyse 3D anatomy of the fused hip based on pre-operative computed tomography (CT) scans, functional outcomes based on the Harris Hip Score (HHS) and the Hip Disability and Osteoarthritis Outcome Score (HOOS), modifications of hip anatomy based on post-operative standardised radiography, and determine complication rate and long-term survival based on Kaplan-Meier analysis.

Methods We retrospectively studied 23 hips that underwent conversion of a fused hip to THA using a 3D CT scan-based custom titanium (Ti alloy hypoxyapetite (HA)-coated stem. The mean follow-up was 15 (9-22) years. Femur anteversion ranged from $-29^{\circ}$ to $80^{\circ}$.

Results HHS improved from 59 to 89 points and average range of motion (ROM) was $88^{\circ}$ for flexion. Back pain decreased in $62 \%$, and knee pain decreased in $42 \%$. The mean post-operative leg-length discrepancy was $7.8 \mathrm{~mm}$. No intra-operative complications occurred. One aseptic stem loosening for mechanical failure was observed. The Kaplan-Meier survivorship considering revision for any reasons as the end point was 95.6\% [95\% confidence interval (CI) 92.4-98.8] at 15 years.

Conclusion Custom cementless stems may be an interesting solution to address the particular anatomical features of hip fusion at the time of THA, with an excellent survival rate at 15 years.
\end{abstract}

Keywords Hip fusion · Hip arthrodesis · Total hip arthroplasty · Anatomy · Custom

\section{Introduction}

Fused-hip conversion to total hip arthroplasty (THA) provides reasonable results, improving function and reducing pain [1-3]. However, the overall success and functional improvement following this procedure remain controversial compared with a conventional THA [2, 4-6]. The

$*$ Matthieu Ollivier

ollivier.matthieu@yahoo.fr

\footnotetext{
${ }^{1}$ Department of Orthopaedic Surgery, APHM, Institute for Locomotion, Sainte-Marguerite Hospital, Marseille, France

${ }^{2}$ Aix Marseille Univ, APHM, CNRS, ISM, Sainte-Marguerite Hospital, Institute for Locomotion, Department of Orthopaedics and Traumatology, , Marseille, France

${ }^{3}$ Institut du Mouvement et de l'Appareil Locomoteur, CHU Sainte Marguerite, 270 Bd Saint Marguerite, 13009 Marseille, France
}

procedure remains technically demanding and is associated with a high complication rate $[4,7,8]$. Previous studies analysed factors that affected post-operative outcomes [9-11] and focused on the results of cemented femoral fixation, with survival rate without failure ranging from 74 to $96 \%$ at 10 years [2, 12]. However, no study reported specifically results of cementless fixation in this specific indication. We previously reported the results of $3 \mathrm{D}$, individually designed cementless stems for patient with abnormal anatomy and/or high functional demand [13-15]. It was our hypothesis that custom cementless stems may be an interesting solution to address the particular anatomical features of fused hip. Therefore, we aimed to analyse:

1. Three-dimensional anatomy of the fused hip based on preoperative computed tomography (CT) scan

2. Functional outcomes based on Harris Hip Score (HHS) and Hip Disability and Osteoarthritis Outcome Score(HOOS) 
3. Modifications of hip anatomy based on post-operative standardised radiography

4. Complication rate and long-term survivorship based on Kaplan-Meier analysis

\section{Materials and methods}

After local ethic committee approval, we retrospectively identified in a prospectively collected database, 23 hips (23 patients; 13 men and ten women) who underwent conversion from fused hip to THA with a custom femoral implant [titanium (Ti) alloy, hydroxyapatite (HA)-coated stem; 3D CT scan based] between January 1992 and December 2005. Mean patient age was $49 \pm 9$ years (28-69) and body mass index (BMI) $25 \pm \mathrm{kg} / \mathrm{m}^{2}$ (19-33). Mean time from fusion to THA was $32 \pm 8$ years (7-56). The initial indication for fusion included 13 infections (11 tuberculosis) with five spontaneous and eight surgical fusions, six post-traumatic, (of which three were surgical), three congenital dislocations of the hip (all surgical fusions), and one sequelae of Legg-Perthes-Calve disease. Thirteen patients $(55 \%)$ had undergone at least one previous hip surgery. Six of those had retained hardware (four with screws between the former femoral head and acetabulum, and two with a plate). At the time of surgery, 13 patients $(55 \%)$ presented with back pain: three with a fixed scoliosis, 15 $(65 \%)$ with knee pain (nine ipsilateral, four bilateral, two contralateral) and four (17\%) from contralateral hip pain.

Before surgery, all patients underwent X-rays and CT scan for prosthesis design. The radiographic analysis included pelvic anteroposterior (AP) and lateral views of both hips and long-axis $\mathrm{X}$-rays of both lower limbs. The AP view allowed the surgeon to choose frontal femoral offset targeting contralateral offset. In case of an abnormal contralateral hip, an abductor level ratio of 0.5 according to Amstutz [16] was set. Leg-length discrepancies were evaluated on long-axis X-rays to equalise leg length during THA. Pre-operative CT scan allowed 3D anatomy evaluation and implant design according to a previously validated and published method [13, 14]. Two professional engineers analysed all CT scans using dedicated software, including artifact elimination from retained hardware that did not interfere with the process. Implant technical specifications were determined based on CT scan analysis to restore extramedullary parameters (lower-limb discrepancy, femoral offset, femoral neck version) and ensure primary implant stability.

All operations were performed through an anterolateral Watson-Jones approach with the patient in a supine position. A trochanteric osteotomy was performed when the preoperative CT scan showed a posterior location of the greater trochanter (related to an excessive version of the upper femur) or when tension of the abductor muscles was considered in- sufficient (nine cases; 37\%). The same hemispheric Ti alloy 
Switzerland) was planned for all cases. Due to insufficient bone coverage, revision implants with a hook in the obturator foramen and superolateral screws were used in four cases (17\%: Hilock rev, Symbios ${ }^{\circledR}$, Switzerland). No bone grafting of the acetabulum was required. The medullary canal was prepared with a smooth, dedicated custom broach, which exactly mimics the shape of the final stem. Then, an uncemented custom Ti alloy HA-coated stem (Symbios ${ }^{\circledR}$, Switzerland) was inserted, fitting the intramedullary proximal femoral anatomy and accommodating neck offset to the new centre of the joint for patient according to the 3D CT-based pre-operative planning [23]. Figure 1a-e presents pre-operative radiograph/planning and postoperative imaging of a 45 year-old female patient with left hip pain secondary to a tuberculosis-related hip fusion.

\section{Post-operative analysis}

All patients were evaluated at three months, one year, three years and every five years. Mean follow-up was 15 (9-

22) years. The patients were evaluated pre-operatively using HHS [17] and post-operatively using HHS and HOOS [18]. Range of motion (ROM) was evaluated with particular care. Abductor strength was evaluated using a standard scale for manual muscle testing (from 0 to 5 points) after conversion. Evaluation of impact of THA on back, knee or contralateral hip pain was recorded. Complications including dislocation, infection or nerve palsy were recorded.

Radiographic post-operative evaluation was performed on AP views of the hip and pelvis and on a true lateral view of the hip. The first post-operative radiograph was then used as a baseline from which subsequent radiographs were interpreted. Leg-length discrepancy was assessed according to Postel [19]. Stem osseointegration was analysed according to the seven zones described by Gruen [20] and the corresponding seven zones on the lateral radiograph. Progressive radiolucencies, or radiolucencies $>2 \mathrm{~mm}$ wide and signs of osteolysis were recorded. Femoral component stability was evaluated by the criteria of Engh et al. [21]. We considered a stem loose if subsidence was $>2 \mathrm{~mm}$ or if the angular position of the stem shifted $>2^{\circ}$. Ossifications were analysed and classified ac- cording to Brooker classification [22].

\section{Statistical analysis}

We described parameters of interest using means and standard deviations (SD) or medians and ranges for continuous vari- ables (age, BMI, HHS, HOOS, postoperative leg lengths) and counts (\%) for categorical variables (gender, side, satisfaction score, radiolucencies, osteolysis). The influence of time from fusion, previous surgery and demographic parameters on post- operative 
a

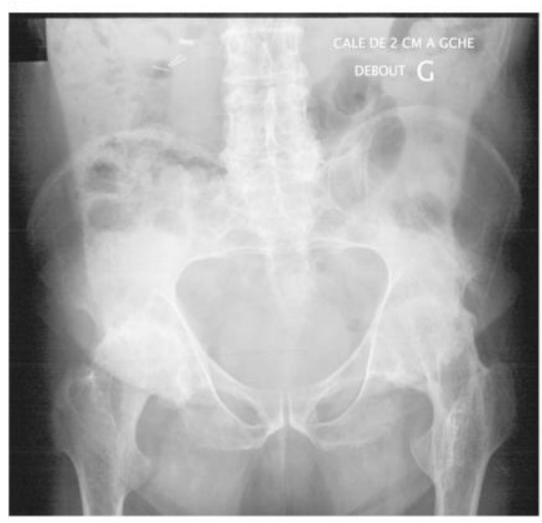

b

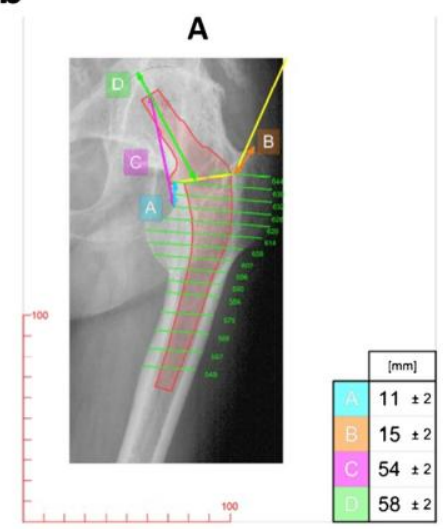

C
B

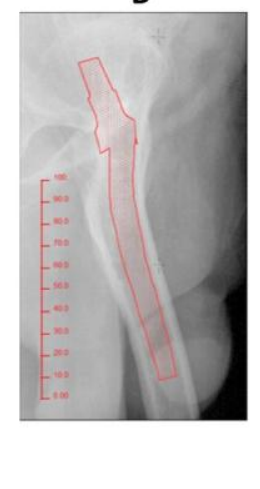

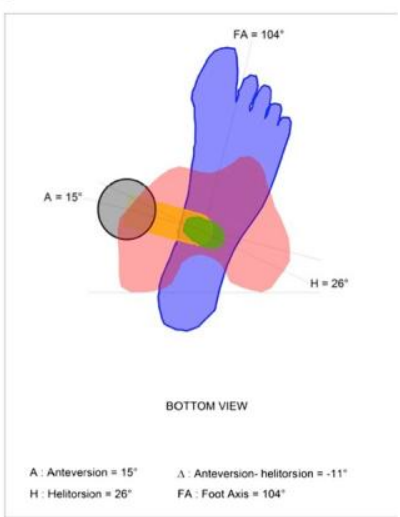

d

Cup Planning - Lewinnek Frame Orientation
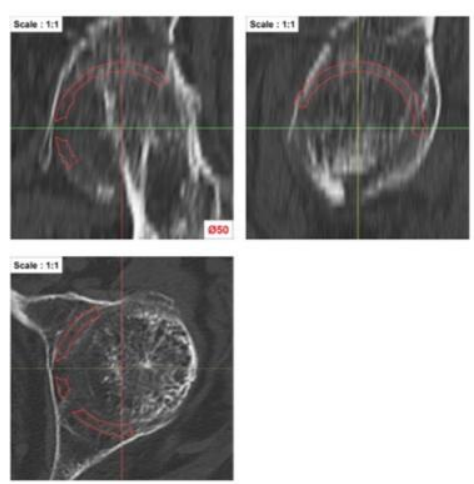

Cup Parameters

\begin{tabular}{ccc} 
& Lewinnek Frame & Supine Patient Position \\
Cup incin & $43^{\circ}$ & $44^{\circ}$ \\
\hline Cup & $46^{\circ}$ & $10^{\circ}$
\end{tabular}

Fig. 1 a-e Pre-operative radiographs/planning, and post-operative imaging of a 45-year-old female patient with left hip pain secondary to a left tuberculosis-related hip fusion a Pre-operative pelvic anteroposterior (AP) view of a left fused hip scheduled for total hip arthroplasty (THA), b Pre-operative planning showing the distance to be respected intra-operatively to restore hip anatomy. c Superimposing the three computed tomography (CT) views of the osteotomy level

We performed a 15-year survival analysis using the KaplanMeier technique [23] with 95\% confidence intervals (CI) considering revision for any reason or radiographic loosening as the end point. Analysis was performed using SPSS software (Version 12; SPSS Inc., Chicago, IL, USA). All calculations assumed two-tailed tests.

\section{Results}

\section{Pre-operative radiographic and CT scan analysis}

According to the radiographic analysis, the recommended lengthening to equalise limb length was $21 \pm 12 \mathrm{~mm}$ ( -5 to $+50 \mathrm{~mm}$ ). The necessary lateral correction (offset) ranged from -12 to $24 \mathrm{~mm}$. Anteversion evaluated on CT scan averaged $17 \pm 11^{\circ}\left(-29^{\circ}\right.$ to $\left.80^{\circ}\right)$; therefore, the necessary (usually above the lesser trochanter), and of the knee and foot levels, it is possible to calculate the correction angle to add (or subtract) to the helitorsion angle such that a final prosthetic anteversion angle of $15^{\circ}$ is achieved. In this case, the helitorsion angle is $26^{\circ}$ and the final prosthetic angle is $15^{\circ}$. The correction in the neck (alpha angle) is $-11^{\circ}$ (retroverted). $\mathrm{d}$ This view is useful to assess the AP size of the cup, its inclination and anteversion. e Post-operative view at 11 years of follow-up

correction in the prosthetic neck to restore the desired neck anteversion $\left(15^{\circ}\right)$ averaged $-2 \pm 10^{\circ}\left(-65\right.$ to $\left.46^{\circ}\right)$.

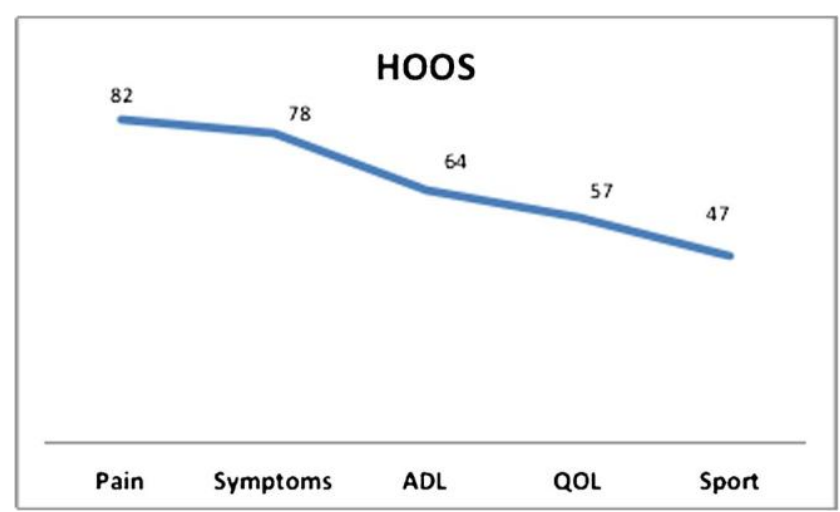

Fig. 2 Results of last follow-up Hip Disability and Osteoarthritis Outcome Score (HOOS) analysis 


\section{Clinical results}

HHS improved from 59 (40-84) to 89 (75-100) points $(p<$ $0.0001)$. HOOS results are presented in Fig. 2. Twenty-one patients $(91 \%)$ were pain free, and three $(9 \%)$ had occasional pain. Back pain decreased in eight patients (62\% with pre-operative back pain). Knee pain decreased in eight patients ( $42 \%$ with preoperative knee pain) and increased in seven ( $40 \%$ with preoperative knee pain) that further required a knee arthroplasty. Conversely, contralateral hip pain decreased in only one of four (25\%) patients with pre-operative contralateral hip pain. ROM analysis and post-operative hip function are presented in Table 1.

In our multivariate model, previous surgery and time from fusion did not influence ROM (respectively, $p=0.12$ and $p=$ 0.18 ) or post-operative limping (respectively, $p=0.12$ and $p=$ $0.18)$.

\section{Post-operative radiographic analysis}

The mean leg-length discrepancy was $7.8 \pm 2.3 \mathrm{~mm}(0-$ $12 \mathrm{~mm}$ ). Eighteen patients $(78 \%)$ had a discrepancy $<5 \mathrm{~mm}$. The abductor lever arm ratio averaged $0.61 \pm 0.12(0.5-0.7)$, with all patients having a ratio $>0.5$. Three ossifications $(13 \%)$ were observed (two grade 1 and one grade 3 ) according to Brooker [22]. One hip (4\%) exhibited osteolysis in zone 7 according to Gruen [20]. No radiolucency was recorded.

\section{Complications and survival}

No intra-operative complications occurred. One early infection occurred and was treated by early lavage-debridement without implant revision. No dislocation occurred. One zirconia head fracture (4\%) occurred and required liner and femoral head exchange with components retained. One aseptic stem loosening was observed at 11 years. The Kaplan-Meier

Table 1 Post-operative range of motion and muscular evaluation

Post-operative evaluation

\begin{tabular}{lll}
\hline Flexion & $88\left(50-130^{\circ}\right)$ & $\begin{array}{l}48 \%(N=11)>90^{\circ} \\
22 \%(N=5) 51-90^{\circ} \\
\end{array}$ \\
& & $30 \%(N=7)<50^{\circ}$ \\
Abduction & $30\left(25-45^{\circ}\right)$ & \\
Adduction & $30\left(20-45^{\circ}\right)$ & \\
External rotation & $40\left(20-60^{\circ}\right)$ & \\
Internal rotation & $40\left(15-60^{\circ}\right)$ & \\
Abductor strength & $56 \%(N=13) 5 / 5$ \\
& $30 \%(N=7) 4 / 5$ & \\
& $8 \%(N=2) 2 / 5$ & \\
Limping & $3 \%(N=1) 1 / 5$ & $13 \%(N=3)$ Trendelemburg \\
& & $21 \%(N=5)$ pelvic obliquity \\
\hline
\end{tabular}

survivorship with revision for any reason as the end point was $95.6 \%$ (CI 92.498.8) at 15 years.

\section{Discussion}

While some authors described conversion of hip fusion to THA as a satisfactory procedure [2, 24, 25], others found that ROM, muscle strength, persistence of limp and need for assistive walking aids are less satisfactory than in primary conventional THA $[6,11,26]$. It was our hypothesis that custom cementless stems may be an interesting solution to address the particular anatomical features of fused hip, allowing uncemented fixation in extreme anatomical abnormalities.

Limited information is available for the surgeon regarding the femoral anatomy of fused hips. However, it could be useful to recognise the femoral abnormalities to anticipate the type of components to use [10, 27]. Kim et al. [27] reported the use of cementless THA in patients with limited anatomic deformities and relatively normal-sized acetabula, whereas cemented THA were performed in patients with more severe anatomical deformities and small femoral canals.

The effectiveness of THA after hip fusion on pain has been shown by several studies. Kim et al. [27] stated that 81 of 86 patients (94\%) had complete or nearly complete relief of back pain post-operatively and that 28 of 38 patients (74\%) had complete or nearly complete relief of knee pain post-operatively. This corroborates with our results, since back pain decreased in $62 \%$ of patients and knee pain in $42 \%$. Regarding pain and function in the surgically treated hip: the literature shows that $79-85 \%$ of hips were pain free or with minimal pain [1-3]. In our study, pain relief was obtained for $91 \%$ of hips, with a possible role of optimal femoral offset, hip versions and leg-length restoration allowed by our individual prosthetic design. Overall function of the operated hip and walking possibilities improved after conversion [25, 28], reaching a global HHS comparable with primary THA for overall indications. Thus, if pain relief and overall function represent the main goals of this procedure, the satisfaction rate for patients undergoing those procedure are not perfect $[1,6$, $8,10,29]$. Amstutz and Sakai [16] in an earlier reportnoted that function restoration (ROM, leg length and limp correction) was worse than those of conventional primary THA. Richards et al. [6] confirmed lower satisfaction scores in their fused patients compared with more standard indications ROM may be significantly improved, reaching $79 \%$ good to excellent, or obtaining an average post-operative hip flexion between 70 and $102^{\circ}[3,10,25,29]$. In our study, flexion averaged $88^{\circ}$, with $79 \%$ of patients having flexion $>70^{\circ}$. No relationship was found between post-operative flexion and presence of previous surgeries or time from fusion. Postoperative strength of the abductor is probably multifactorial in this population: in a series of 15 patients, Schafer et al. [30] 
found the post-operative Trendelenburg sign to be moderate to severe in seven (47\%). In our study, eight patients (12.5\%) had a post-operative Trendelenburg sign, and strength of the abductor was graded as $5 / 5$ or $4 / 5$ in 21 patients $(87.5 \%)$. In the study of Fernandez et al. [5], none was graded as 5/5, and 30 patients were graded $4 / 5(62 \%)$. This was significantly different compared with a primary THA control group, who presented better abductor muscle strength ( $5 / 5$ in ten patients, $4 / 5$ in 23). Eighteen patients ( $37 \%$ ) had a positive Trendelenburg sign in their study. We hypothesised that individual restoration of both femoral offset and anteversion, with respect to lower limb equalisation, may positively influence our good results on muscle strength.

In our series, pre-operative CT-scan-based implants allowed a cementless fixation in all cases; recommended lengthening ranged from -5 to $+50 \mathrm{~mm}$, lateral offset correction from -12 to $24 \mathrm{~mm}$ and the necessary correction in the prosthetic neck to restore the desired normal neck anteversion from -65 to $44^{\circ}$. Post-operative complications were not rare (26\%) and included three heterotopic ossifications, one deep infection, one zirconium head fracture and one aseptic loosening. Conversely, the rate of intra-operative complication was very low; e.g., no intra-operative fracture was observed. This is in contradiction with recent literature results [31, 32], and we hypothesise that the use of custom prothesis designed to fit perfectly with intramedullary anatomy may explain those differences.

Few data are available on mid- to long-term results of cementless THA for hip fusion in the literature, long-term results being mostly available with cemented techniques [33, 34]. Survival of fusion takedown THAs ranges from $74 \%$ to $96 \%$ at ten years $[2,6,10]$ and $73 \%$ at 26 years [2]. Sochart and Porter [34] reported good long-term results of Charnley total hip replacement in patients with spontaneous fusion by ankylosing spondylitis. In their series, the probability that both components would survive was $91 \%$ at ten years, $73 \%$ at 20 years, and $70 \%$ at 30 years [32]. However, in two reports at 7- [4] and ten year [8] follow-up, the rates of failure were high, particularly in younger patients and in patients who had one or more previous operations. Considering only aseptic loosening as an endpoint, survival of this cementless custom stem was 95.6\% (CI 92.498.8 ) at 15 years, comparing favourably with the literature [2, 4, $6,30]$. Our results were not influenced by the nature of arthrodesis, conversely to the conclusion of Strathy and Fitzgerald [8] in 80 patients, at a mean ten year follow-up. With a failure rate of $26 \%$, they concluded that spontaneous arthrodesis had a better prognosis for longevity of the arthroplasty and higher hip scores. They also found an inverse relationship between failure rate and duration of arthrodesis. Patient age at the time of arthrodesis was another factor that influenced the results of conversion to arthroplasty. Patients $>50$ years presented a lower failure rate and a better survivorship. Their findings were partly corroborated by Peterson et al. [26]. Thus, it would appear that lower age and longer interval between arthrodesis and arthroplasty have a substantially negative impact on long-term implant survival. These results have not been corroborated by our study, potentially due to the limited number of patients.

The limitations of this study include lack of control group to directly compare functional results with those of patients operated upon for primary osteoarthritis (OA) or dysplastic development of the hip. Secondly, the retrospective design of our series exposed our results to methodological bias, such as evaluation bias. Thirdly, the number of patient is low; however, this series represents a 13-year continuous inclusion period of a high-volume institution without a patient lost to follow-up.

The results of our study supported our hypothesis that custom cementless stems may be an interesting solution to address the particular anatomical features of fused hip at the time of THA, with an excellent survival rate at 15 years.

\section{Compliance with ethical standards}

Conflict of interest Jean-Noel Argenson is educational consultant for Symbios.

All of the other authors have nothing to disclose regarding the present manuscript.

\section{References}

1. Jain S, Giannoudis PV (2013) Arthrodesis of the hip and conversion to total hip arthroplasty: a systematic review. J Arthroplast 28: 1596-1602. https://doi.org/10.1016/j.arth.2013.01.025

2. Joshi AB, Markovic L, Hardinge K, Murphy JCM (2002) Conversion of a fused hip to total hip arthroplasty. J Bone Joint Surg Am 84-A:1335-1341

3. Lustig S, Vaz G, Guyen O, Tayot O, Chavane H, Bejui-Hugues J et al (2007) Total hip arthroplasty after hip arthrodesis performed for septic arthritis. Rev Chir Orthop Reparatrice Appar Mot 93: 828-835

4. Kilgus DJ, Amstutz HC, Wolgin MA, Dorey FJ (1990) Joint replacement for ankylosed hips. J Bone Joint Surg Am 72:45-54

5. Fernandez-Fairen M, Murcia-Mazón A, Torres A, Querales V, Murcia A (2011) Is total hip arthroplasty after hip arthrodesis as good as primary arthroplasty? Clin Orthop Relat Res 469:19711983. https://doi.org/10.1007/s11999-010-1704-y

6. Richards CJ, Duncan CP (2011) Conversion of hip arthrodesis to total hip arthroplasty: survivorship and clinical outcome. J Arthroplast 26:409-413. https://doi.org/10.1016/j. arth.2010.02.005

7. Kreder HJ, Williams JI, Jaglal S, Axcell T, Stephen (1999) A population study in the province of Ontario of the complications after conversion of hip or knee arthrodesis to total joint replacement. Can J Surg 42:433-439

8. Strathy GM, Fitzgerald RH (1988) Total hip arthroplasty in the ankylosed hip. A ten-year follow-up. J Bone Joint Surg Am 70: 963-966

9. Schuh A, Zeiler G, Werber S (2005) Results and experiences of conversion of hip arthrodesis. Orthopade 34:218, 220-4. https:// doi.org/10.1007/s00132-004-0723-3

10. Morsi E (2007) Total hip arthroplasty for fused hips; planning and techniques. J Arthroplast 22:871-875. https://doi.org/10.1016/j. arth.2006.09.003 
11. Reikerås O, Bjerkreim I, Gundersson R (1995) Total hip arthroplasty for arthrodesed hips. 5- to 13-year results. J Arthroplast 10:529-531

12. Hamadouche M, Kerboull L, Meunier A, Courpied JP, Kerboull M (2001) Total hip arthroplasty for the treatment of ankylosed hips : a five to twenty-one-year follow-up study. J Bone Joint Surg Am 83A:992-998

13. Flecher X, Pearce O, Parratte S, Aubaniac J-M, Argenson J-N (2010) Custom cementless stem improves hip function in young patients at 15-year followup. Clin Orthop Relat Res 468:747-755. https://doi.org/10.1007/s11999-009-1045-X

14. Flecher X, Parratte S, Aubaniac J-M, Argenson J-N (2007) Threedimensional custom-designed cementless femoral stemfor osteoarthritis secondary to congenital dislocation of the hip. J Bone Joint Surg (Br) 89:1586-1591. https://doi.org/10.1302/0301-620X. 89B 12.19252

15. Flecher X, Parratte S, Aubaniac JM, Argenson JN (2007) Cementless total hip arthroplasty using custom stem and reinforcement ring in hip osteoarthritis following developmental dysplasia. Hip Int 17(Suppl 5):S120-S127

16. Amstutz HC, Sakai DN (1975) Total joint replacement for ankylosed hips. Indications, technique, and preliminary results. J Bone Joint Surg Am 57:619-625

17. Harris WH (1969) Traumatic arthritis of the hip after dislocation and acetabular fractures: treatment by mold arthroplasty. An endresult study using a new method of result evaluation. J Bone Joint Surg Am 51:737-755

18. Nilsdotter AK, Lohmander LS, Klässbo M, Roos EM (2003) Hip disability and osteoarthritis outcome score (HOOS)-validity and responsiveness in total hip replacement. BMC Musculoskelet Disord 4:10. https://doi.org/10.1186/1471-2474-4-10

19. Postel M, Courpied JP (1986) Replacement of a failed total hip prosthesis. Rev Rhum Mal Osteoartic 53:133-135

20. Gruen TA, McNeice GM, Amstutz HC (1979) вModes of failure^ of cemented stem-type femoral components: a radiographic analysis of loosening. Clin Orthop Relat Res 141:17-27

21. Engh CA, Massin P, Suthers KE (1990) Roentgenographic assessment of the biologic fixation of porous-surfaced femoral components. Clin Orthop Relat Res 257:107-28.

22. Brooker AF, Bowerman JW, Robinson RA, Riley LH (1973) Ectopic ossification following total hip replacement. Incidence and a method of classification. J Bone Joint Surg Am 55:16291632

23. Bland JM, Altman DG (1998) Survival probabilities (the KaplanMeier method). BMJ 317:1572

24. Hardinge K, Murphy JC, Frenyo S (1986) Conversion of hip fusion to Charnley low-friction arthroplasty. Clin Orthop Relat Res 211: 173-9.

25. Rajaratnam SS, Sexton SA, Waters TS, Walter WL, Zicat BA, Walter WK (2009) Long term results of cementless total hip replacement for reversal of hip ankylosis. Hip Int 19:120-127

26. Peterson ED, Nemanich JP, Altenburg A, Cabanela ME (2009) Hip arthroplasty after previous arthrodesis. Clin Orthop Relat Res 467: 2880-2885. https://doi.org/10.1007/s11999-009-1027-Z

27. Kim Y-H, Oh S-H, Kim J-S, Lee S-H (2003) Total hip arthroplasty for the treatment of osseous ankylosed hips. Clin Orthop Relat Res 414:136-48 doi:https://doi.org/10.1097/01.blo.0000081935.75404. $7 \mathrm{f}$

28. Rittmeister M, Starker M, Zichner L (2000) Hip and knee replacement after longstanding hip arthrodesis. Clin Orthop Relat Res: 136-145

29. Sirikonda SP, Beardmore SP, Hodgkinson JP (2008) Role of hip arthrodesis in current practice: long term results following conversion to total hip arthroplasty. Hip Int 18:263-271

30. Schäfer D, Dick W, Morscher E (2000) Total hip arthroplasty after arthrodesis of the hip joint. Arch Orthop Trauma Surg 120:176-178

31. Villanueva M, Sobrón FB, Parra J, Rojo JM, Chana F, Vaquero J (2013) Conversion of arthrodesis to Total hip arthroplasty: clinical outcome, complications, and prognostic factors of 21 consecutive cases. HSS J 9:138-144. https://doi.org/10.1007/s11420-013-93303

32. Jauregui JJ, Kim JK, Shield WP 3rd, Harb M, Illical EM, Adib F, Maheshwari AV (2017) Hip fusion takedown to a total hip arthroplasty-is it worth it? A systematic review. Int Orthop 41: 1535-1542. https://doi.org/10.1007/s00264-017-3436-Z

33. Besser MI (1982) A muscle transfer to replace absent abductors in the conversion of a fused hip to a total hip arthroplasty. Clin Orthop Relat Res 162:173-4

34. Sochart DH, Porter ML (1997) Long-term results of total hip replacement in young patients who had ankylosing spondylitis. Eighteen to thirty-year results with survivorship analysis. J Bone Joint Surg Am 79:1181-1189 